\title{
Ubiquitin-Proteasome-Mediated Synaptic Reorganization: A Novel Mechanism Underlying Rapid Ischemic Tolerance
}

\author{
Robert Meller, ${ }^{1}$ Simon John Thompson, ${ }^{1}$ Theresa Ann Lusardi, ${ }^{1}$ Andrea Nicole Ordonez, ${ }^{1}$ Michelle Dawn Ashley, ${ }^{1}$ \\ Veronica Jessick, ${ }^{1}$ Weihzen Wang, ${ }^{1}$ Daniel John Torrey, ${ }^{1}$ David Clifford Henshall,,${ }^{1,2}$ Philip R. Gafken, ${ }^{3}$ \\ Julie Anne Saugstad, ${ }^{1}$ Zhi-Gang Xiong, ${ }^{1}$ and Roger Pancoast Simon ${ }^{1}$ \\ ${ }^{1}$ Robert S. Dow Neurobiology Laboratories, Legacy Research, Portland, Oregon 97232, ${ }^{2}$ Royal College of Surgeons Ireland, Dublin 2, Ireland, and \\ ${ }^{3}$ Proteomics Facility, Fred Hutchinson Cancer Research Center, Seattle, Washington 98109
}

Ischemic tolerance is an endogenous neuroprotective mechanism in brain and other organs, whereby prior exposure to brief ischemia produces resilience to subsequent normally injurious ischemia. Although many molecular mechanisms mediate delayed (genemediated) ischemic tolerance, the mechanisms underlying rapid (protein synthesis-independent) ischemic tolerance are relatively unknown. Here we describe a novel mechanism for the induction of rapid ischemic tolerance mediated by the ubiquitin-proteasome system. Rapid ischemic tolerance is blocked by multiple proteasome inhibitors [carbobenzoxy-L-leucyl-L-leucyl-L-leucinal (MG132), MG115 (carbobenzoxy-L-leucyl-L-leucyl-L-norvalinal), and clasto-lactacystin- $\beta$-lactone]. A proteomics strategy was used to identify ubiquitinated proteins after preconditioning ischemia. We focused our studies on two actin-binding proteins of the postsynaptic density that were ubiquitinated after rapid preconditioning: myristoylated, alanine-rich C-kinase substrate (MARCKS) and fascin. Immunoblots confirm the degradation of MARCKS and fascin after preconditioning ischemia. The loss of actin-binding proteins promoted actin reorganization in the postsynaptic density and transient retraction of dendritic spines. This rapid and reversible synaptic remodeling reduced NMDA-mediated electrophysiological responses and renders the cells refractory to NMDA receptor-mediated toxicity. The dendritic spine retraction and NMDA neuroprotection after preconditioning ischemia are blocked by actin stabilization with jasplakinolide, as well as proteasome inhibition with MG132. Together these data suggest that rapid tolerance results from changes to the postsynaptic density mediated by the ubiquitin-proteasome system, rendering neurons resistant to excitotoxicity.

Key words: ischemia; actin; NMDA; proteasome; dendritic spines; ubiquitin; ischemia

\section{Introduction}

Stroke is the third leading cause of death in the United States today (American Heart Association, 2003). It is a disorder without effective acute neuroprotective treatment. For this reason, attention has recently been brought to defining the brain's own evolutionarily conserved endogenous neuroprotective mechanisms that occur in ischemic tolerance or after ischemic preconditioning. In these settings, previous exposure to a nonharmful duration of ischemia renders the brain resilient to a subsequent harmful ischemic episode (Kitagawa et al., 1990; Dirnagl et al., 2003). Prolonged ischemia results in excitotoxic/programmed cell death (Choi, 1992), and mechanisms of ischemic tolerance would be expected to inhibit these cellular processes.

Two mechanisms of ischemic tolerance have been described. Classic, or delayed, ischemic tolerance requires new protein synthesis and results in protection $24-72 \mathrm{~h}$ after the preconditioning stimulus (Barone et al., 1998; Dirnagl et al., 2003; Meller et al.,

Received March 23, 2007; revised 0ct. 22, 2007; accepted Nov. 1, 2007.

This work was supported by National Institutes of Health Grants NS050669 and NS054023 (R.M.), NSO24728 (R.P.S.), and American Heart Association Grant $0465430 Z$ (R.M.).

Correspondence should be addressed to Robert Meller, Robert S. Dow Neurobiology Laboratories, Legacy Research, Portland, OR 97232. E-mail: rmeller@downeurobiology.org.

DOI:10.1523/JNEUROSCI.3474-07.2008

Copyright $\odot 2008$ Society for Neuroscience $\quad$ 0270-6474/08/280050-10\$15.00/0
2005). In contrast, rapid ischemic tolerance does not require new protein synthesis and produces neuroprotection within $1 \mathrm{~h}$ of the preconditioning event (Perez-Pinzon et al., 1996; Reshef et al., 1996; Perez-Pinzon and Born, 1999; Meller et al., 2006). The relatively short time required for induction of rapid ischemic tolerance suggests that it is regulated by posttranslational neurochemical events. In addition, rapid ischemic tolerance reduces the activation of programmed cell death-associated caspases (caspase3) after normally harmful ischemia (Meller et al., 2006).

The ubiquitin-proteasome system is the cell's major extralysosomal system for protein degradation (Verma and Deshaies, 2000; Herrmann et al., 2007). The addition of poly-ubiquitin chains to a protein results in its translocation to the proteasome, a large multisubunit protease, for degradation. We have recently identified the ubiquitin-proteasome system as playing an essential role in rapid tolerance to ischemia. Tolerance to ischemia can occur via the selective ubiquitination and degradation of a cell death-associated protein, Bcl-2-interacting mediator of cell death (Bim). Rapid ischemic tolerance and Bim degradation occurs independently of new protein synthesis and is blocked by the proteasome inhibitor carbobenzoxy-L-leucyl-L-leucyl-L-leucinal (MG132) (Meller et al., 2006).

Here we further pursue the role of the ubiquitin/proteasome system in mediating rapid molecular and cellular changes after 
preconditioning ischemia (PC), which may underlie the neuroprotective phenotype of rapid ischemic tolerance. Accordingly, a proteomic analysis of preconditioned neuronal cultures was performed to identify proteins ubiquitinated after preconditioning ischemia. In our study, the majority of identified proteins have a role in the form and function of the postsynaptic density. We therefore focused our study of this proteomic analysis on two ubiquitinated proteins that had a structural relationship to the postsynaptic density: MARCKS and fascin. Here we show that after a preconditioning duration of ischemia/reperfusion, the ubiquitination and degradation of cellular proteins results in the reorganization of the actin cytoskeleton and remodeling of postsynaptic dendrite architecture, with a resultant selective attenuation of toxic NMDA receptor-mediated signaling at the time when tolerance to ischemia is acquired.

\section{Materials and Methods}

Cell culture. Cortical neuronal cultures were prepared from 1- to 2-d-old Sprague Dawley rat pups using previously described methods (Meller et al., 2006). All experiments were performed in accordance with the American animal protection legislation and approved by the Legacy Health System Institutional Animal Care and Use Committee. For all experiments, cells were used after 10-14 d in culture, when cultures consist of $\sim 80-90 \%$ neurons. For Western blotting, P62 pull-down, and immunoprecipitation experiments, cells were plated out onto 3.5 or $6 \mathrm{~cm}$ polyD-lysine-coated culture dishes (Primera; BD Biosciences, San Jose, CA). For oxygen and glucose deprivation (OGD) experiments, cells were washed twice in PBS (0.5 mM $\mathrm{CaCl}_{2}, 1 \mathrm{mM} \mathrm{MgCl}_{2} ; \mathrm{pH}$ 7.4) and then incubated for various times in an anaerobic chamber (Forma Scientific, Marietta, $\mathrm{OH})\left(85 \% \mathrm{~N}_{2}, 5 \% \mathrm{H}_{2}, 10 \% \mathrm{CO}_{2} ; 35^{\circ} \mathrm{C}\right)$ in $\mathrm{PBS}$ at $37^{\circ} \mathrm{C}$. After ischemia, cells were replenished with Neurobasal A media and placed into a normoxic incubator.

Some cells were incubated with pharmacological compounds for $1 \mathrm{~h}$ during the recovery phase after $30 \mathrm{~min}$ of tolerance-inducing OGD and before 120 min of harmful ischemia (Fig. 1 A). MG132 and jasplakinolide were purchased from EMD Biosciences (San Diego, CA), carbobenzoxyL-leucyl-L-leucyl-L-norvalinal (MG115) and clasto-lactacystin- $\beta$-lactone were purchased from Biomol (Plymouth Meeting, PA).

Cell death assay. Cell death was assessed by propidium iodide (PI) exclusion as previously described (Meller et al., 2005, 2006). Briefly, cells are incubated with propidium iodide $(1.5 \mu \mathrm{g} / \mathrm{ml}$ in PBS; Sigma, St. Louis, $\mathrm{MO}$ ) for $3 \mathrm{~min}$, then fixed in $4 \%$ formalin at room temperature, permeabilized in $0.1 \%$ Triton X-100/PBS and mounted in $4^{\prime}, 6^{\prime}$-diamidino-2phenylindole (DAPI)-containing media (Vector Laboratories, Burlingame, CA). Cells were visualized using a Leica (Bannockburn, IL) microscope under excitation/emission (Ex/Em) wavelengths of 340/425 $\mathrm{nm}$ (blue) and 580/630 $\mathrm{nm}$ (red), respectively. Images were collected using an Optronics DEI-750 three-chip camera equipped with a BQ 8000 sVGA frame grabber and analyzed using Bioquant (Nashville, TN). PIpositive cells are expressed as a percentage of the total number of cells in the view (DAPI positive). The average of three random views of a coverslip was assessed and counted for each data point, and experiments were repeated on $n$ independent sets of cultures.

Ubiquitin proteome analysis. Cell lysates $(10 \mathrm{mg})$ were prepared in a radioimmunoprecipitation assay buffer (Meller et al., 2005), cleared, and then incubated for $2 \mathrm{~h}$ at $4^{\circ} \mathrm{C}$ with P62 UBA beads (Biomol). MG132 was included during the recovery to prevent degradation of ubiquitinated proteins. Precipitated proteins were subject to PAGE, and gel sections (approximate $10-30 \mathrm{kDa}$ gel fragments) were analyzed at the proteomics facility at the Fred Hutchinson Cancer Research Center (Seattle, WA). Unstained gel slices were washed twice with water, and "in-gel" protein digestion was performed as described previously (Shevchenko et al., 1996), but omitting the reduction and alkylation steps. Samples were desalted using micro C18 ZipTips (Millipore, Billerica, MA) and dried, and resuspended in $5 \mu \mathrm{l}$ of $0.1 \%$ trifluoroacetic acid and analyzed by liquid chromatography electrospray ionization tandem mass spectrometry (LC/ESI MS/MS) with a LCQ “classic" mass spectrometer (Thermo-
Electron, Pittsburgh, PA) using a previously described instrument configuration (Gatlin et al., 1998). Data were collected in a data-dependent mode in which an MS scan was followed by MS/MS scans of the three most abundant ions from the preceding MS scan. Mass spectrometry data were searched against rat or human protein databases (subsets of proteins from the National Center for Biotechnology Information nonredundant protein database) using the software search algorithm COMET (Institute for Systems Biology). COMET results were considered valid if at least two unique peptides identified back to a protein and if the peptide matches had raw scores $>200$ for +1 ions, 300 for +2 ions, and 300 for +3 ions, $Z$-scores $>4, \mathrm{dN}>0.1$, and $\%$ ions of $>30 \%$, and the identification did not appear in a control sample from a blank portion of the gel. Proteins present in both control and OGD-treated samples were omitted from further analysis (supplemental Table 1, available at www. jneurosci.org as supplemental material).

Explanation of COMET filter parameters. To determine the $Z$-score, the dot product between the experimental spectrum and a theoretical spectrum is determined, with the resulting score scaled to $1000 . Z$-score is the number of SDs away from the mean of the top scoring peptide compared with the top 500 clustered peptide scores. The difference between normalized scores is the $\mathrm{dN}$ value. The $\%$ ionic is the percentage of matched peptide fragment ions over the total number of expected fragments ions for the best matching peptide.

Immunoblotting. Immunoblotting was performed as previously described (Meller et al., 2002). Protein samples $(50 \mu \mathrm{g})$ were denatured, subject to PAGE, and transferred to polyvinylidene difluoride membranes (Bio-Rad, Hercules, CA), before incubation with primary antibodies at $4^{\circ} \mathrm{C}$ overnight; MARCKS, fascin, and actin (Santa Cruz Biotechnology, Santa Cruz, CA), MAP2B (Sigma, St. Louis, MO); NR1, NR2A, NR2B, and PSD-95 (BD Biosciences); and phospho-CREB (Cell Signaling Technology, Beverly MA). Membranes were incubated with anti-rabbit or anti-mouse IgG conjugated to horseradish peroxidase (Cell Signaling Technology). Chemiluminescence (Visualizer Upstate, Charlottesville, VA) was captured and quantified using a Kodak Imagestation 2000RT.

Immunoprecipitation. Capture antibodies $(5 \mu \mathrm{g})$ were cross-linked to protein A agarose using sulfo-SMCC (5 $\mu \mathrm{g}$; Pierce, Rockford, IL), washed, and blocked with $1 \%$ BSA for $30 \mathrm{~min}$ at room temp, before incubating with cell lysates $(750 \mu \mathrm{g})$ overnight at $4^{\circ} \mathrm{C}$. Precipitated proteins were washed using spin columns (Sigma), eluted by boiling in gel loading buffer, then subject to PAGE as for immunoblotting.

Immunocytochemistry, phalloidin, and DiO imaging. Cells were fixed with $4 \%$ formalin, permeabilized with TX-100 (0.01\%), and incubated with either antibodies specific to fascin and MARCKS, or phalloidin (Oregon green 488), according to manufacturer's directions (Invitrogen, Carlsbad, CA). Primary antibodies were detected with specific secondary antibodies conjugated to CY3 or AlexaFluor 488. Immunostaining was studied using a Carl Zeiss Axioimager fitted with EC Plan Neo-Fluar $(40 \times)$ or Plan Apochromat $(100 \times$ oil) objectives under Ex/Em wavelengths of 359/461 nm (blue), 470/509 nm (green), and 550/570 (red). Images were captured using a Zeiss MRM camera and analyzed using Axiovision v4.6 software. Phalloidin staining was studied using a Leica microscope fitted with an objective under Ex/Em wavelengths of 359/461 $\mathrm{nm}$ (blue) and 500/550 $\mathrm{nm}$ (green). To obtain 100× images of phalloidin staining, we used the above Zeiss microscope fitted with an Apotome. Phalloidin images were quantified using ImageJ (http://rsb.info.nih.gov/ ij/). Briefly, images were converted to grayscale 8 bit images and autothresholded to obtain a mask of objects, and objects with an area between 1 and $3.5 \mu \mathrm{m}^{2}$ were counted and the density of objects determined.

Cultures were preincubated with 3,3'-dioctadecyloxacarbocyanine perchlorate (DiO) (Invitrogen) (25 $\mu \mathrm{g} /$ coverslip suspended in PBS) overnight. Cells were then subject to ischemia and then imaged using a $63 \times$ water-immersion lens (HCX APO L $63.0 \times 0.90 \mathrm{~W}$ ) in a PBS solution containing glucose $(4.5 \mathrm{~g} / \mathrm{L}) . Z$-series stacks were obtained at $0.2 \mu \mathrm{m}$ thickness using the Leica software. Image series were imported into Image $\mathrm{J}(\mathrm{NIH})$ and a $Z$-projection stack compiled of the maximum intensity of staining. The brightness and contrast were adjusted to visualize the spines and other dendritic features. Some cells were recovered in the presence of MG132 (1 $\mu \mathrm{M})$ or jasplakinolide $(1 \mu \mathrm{M})$ for $1 \mathrm{~h}$ before view- 
ing. Numbers of spines were determined per $10 \mu \mathrm{m}$ length of dendrite from multiple dendrite sections from multiple neurons in $n$ independent experiments. Primary dendrites were defined as those directly abutting the cell soma, secondary dendrites contacted a primary dendrite, and tertiary dendrites contacted a secondary dendrite. Secondary and tertiary dendrites were only counted if their respective primary dendrite was also assessed.

Electrophysiology. Patch-clamp recordings were performed as described previously (Xiong et al., 2004). Patch electrodes, with resistances of $2 \sim 3 \mathrm{M} \Omega$ when filled with intracellular solution, were constructed from thin-walled borosilicate glass $(1.5 \mathrm{~mm}$ diameter, World Precision Instruments, Sarasota, FL). A multibarrel perfusion system (SF-77, Warner Instrument, Hamden, CT) was used to achieve a rapid exchange of extracellular solutions. Whole-cell currents were recorded using Axopatch 200B amplifiers (Axon Instruments, Foster City, CA). Data were filtered at $2 \mathrm{kHz}$ and digitized at $5 \mathrm{~Hz}$ using a Digidata $1320 \mathrm{DAC}$ unit (Axon Instruments). The on-line acquisition was done using pCLAMP software (version 8, Axon Instruments). NMDA currents were activated at $-60 \mathrm{mV}$ by perfusion of neurons with a solution containing $100 \mu \mathrm{M}$ NMDA plus $5 \mu \mathrm{M}$ glycine. For each cell, a voltage step of $-5 \mathrm{mV}$ from the holding potential was applied to monitor the cell capacitance and access resistance. Recordings with access resistance larger than $15 \mathrm{M} \Omega$ were excluded from data analysis.

Data analysis. Data from cell death experiments are reported as mean \pm SEM of $n$ independent experiments. Statistical analysis of cell death and morphological data were performed using one way ANOVA or two-way ANOVA followed by Bonferroni's multiple-comparison test using GraphPad Prism version 4.0 (GraphPad Software, San Diego, CA). Electrophysiology recordings and phalloidin puncta quantification data were analyzed using unpaired two-tailed Student's $t$ test. Statistical significance was accepted at $p<0.05$.

\section{Results}

Rapid ischemic tolerance is mediated by the proteasome

We recently described a role for the ubiquitin-proteasome system in mediating rapid ischemic tolerance (Meller et al., 2006). The rapid ischemic tolerance paradigm is outlined in Figure $1 \mathrm{~A}$. Preconditioning was induced in primary rat neuronal cultures [10-14 $\mathrm{d}$ in vitro (DIV)] by a nonharmful duration (30 $\mathrm{min}$ ) of OGD (Fig. $1 \mathrm{~B}$ ). A longer (120 min) duration of OGD resulted in an increase in PI uptake into cells ( $\sim 55 \%$ cell death) (Fig. $1 B, C)$. Preconditioned rat neuronal cultures were protected against a harmful episode of ischemia (120 min duration) (Fig. 1A-C).

To investigate the role of the ubiquitin-proteasome in rapid ischemic tolerance, some cells were incubated with the proteasome inhibitor MG132. MG132 blocked the neuroprotection acquired in rapid ischemic tolerance when incubated with neurons after 30 min of OGD preconditioning, but before harmful ischemic challenge (Fig. $1 B, C$ ). Similarly, blocking the proteasome with MG115 and clasto-lactacystin- $\beta$-lactone also blocked rapid ischemic tolerance (Fig. $1 B, C$ ). None of these proteasome inhibitors (MG132, MG115, or clasto-lactacystin- $\beta$-lactone) significantly increased cell death in the cultures under basal conditions, when incubated with neuronal cultures for $1 \mathrm{~h}$ (Fig. $1 B, C)$.

\section{Proteomic analysis of ubiquitinated proteins after preconditioning ischemia}

We initiated a proteomic strategy to further identify proteins ubiquitinated after preconditioning ischemia using an unbiased approach. Utilizing a ubiquitin-binding pull-down assay (Meller et al., 2006), we determined changes in protein ubiquitination after preconditioning ischemia. P62 (sequestome-1) shuttles ubiquitinated proteins to the proteasome (Babu et al., 2005). The pull-down of ubiquitinated proteins by P62 ubiquitin binding domain-conjugated agarose beads was confirmed in an ex vivo assay (supplemental Fig. $1 \mathrm{~A}$, available at www.jneurosci.org as

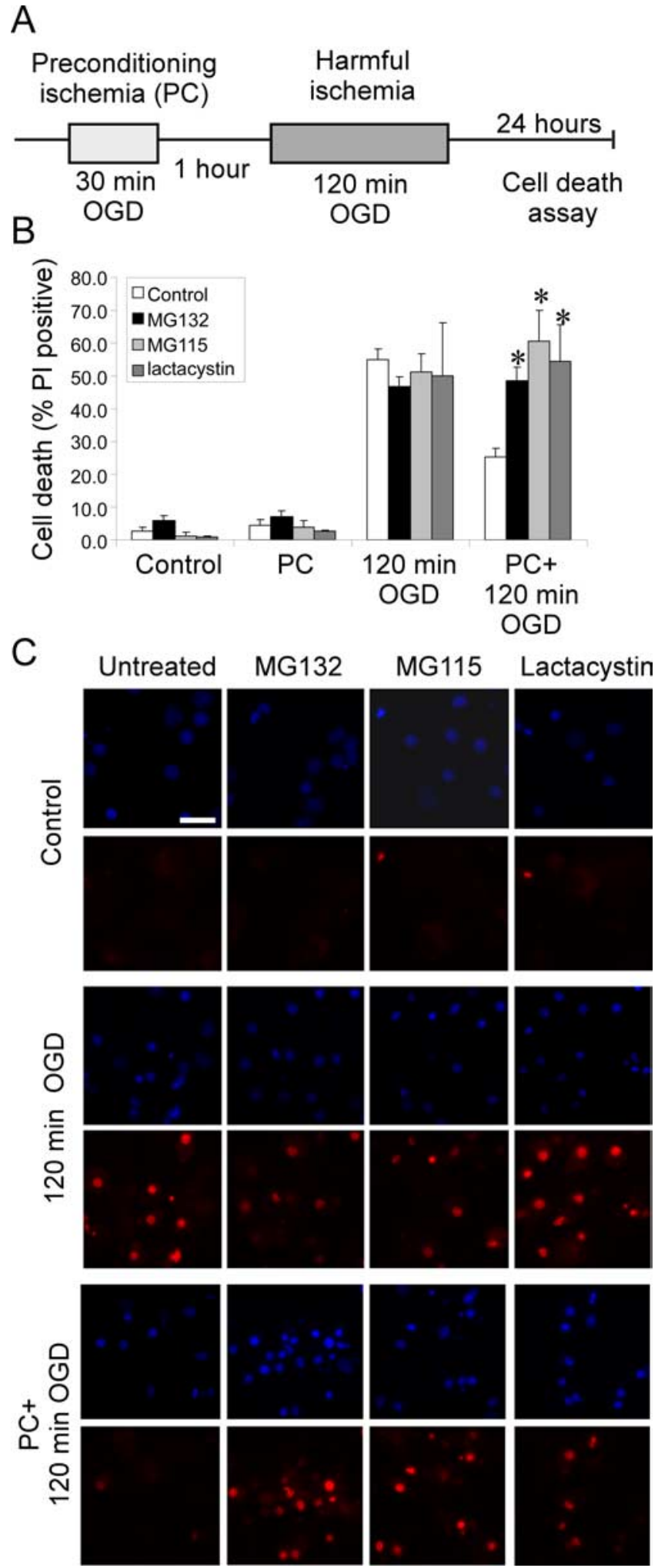

Figure 1. Rapid ischemic tolerance is blocked by proteasome inhibition. $\boldsymbol{A}, \mathrm{Sch}$-matic of the rapid ischemic tolerance paradigm. $P($ ( $30 \mathrm{~min} 0 G \mathrm{G})$ is administered $1 \mathrm{~h}$ before harmful ischemia (120 min 0GD). Cell death is assessed $24 \mathrm{~h}$ later by propidium iodide from exposure to 120 min OGD. B, Addition of the proteasome inhibitors MG132 $(0.1 \mu \mathrm{M}), \mathrm{MG} 115(0.1 \mu \mathrm{M})$, or clastolactacystin- $\beta$-lactone (1 $\mu \mathrm{m}$ ) after preconditioning blocks neuroprotection (data shown are mean \pm SEM; $n=9,5,4$, and 3 independent experiments, respectively; ${ }^{*} p<0.001$ vs $P C+$ $120 \mathrm{~min}$ OGD). C, Representative $40 \times$ images of DAPI- (blue) and propidium iodide- (red) stained cultures. Control, MG132, MG115, or clasto-lactacystin- $\beta$-lactone-treated cells were subject to no ischemia, $120 \mathrm{~min}$ OGD, or PC + $120 \mathrm{~min}$ OGD and recovered for $24 \mathrm{~h}$. Scale bar, 25 $\mu \mathrm{m}$. All experiments were performed on cortical neurons in culture at 10-14 DIV. 
Table 1. Proteins identified in P62 pull-down experiments in control and preconditioned tissue

\begin{tabular}{|c|c|c|c|c|c|}
\hline Treatment & Name & Gl number & Peptides & Unique & Function \\
\hline Control & $\beta$-Tubulin 2 & 33465435 & 2 & 2 & SCM \\
\hline Control & Na,K-ATPase $\alpha$ subunit 3 & 14349292 & 3 & 2 & Met \\
\hline Control & $\beta$-Spectrin & 33303722 & 3 & 3 & $\mathrm{SCM}$ \\
\hline Control & Similar to KIAA1185 protein & 34872773 & 2 & 2 & $\mathrm{TT}(?)$ \\
\hline Control & CYFIP (cytoplasmic Fragile-X interacting family) (rat homolog) & 34870680 & 2 & 2 & $\mathrm{SCM}$ \\
\hline Control & Wave 1 (rat homolog) & 34853415 & 2 & 2 & SCM \\
\hline Control & Sam 68 (src associated in mitosis) & 18426824 & 2 & 2 & TT \\
\hline Preconditioning & Calcineurin (protein phosphatase $2 \mathrm{~B} \alpha$ subunit) & 16758910 & 2 & 2 & ST \\
\hline Preconditioning & Creatine kinase & 31542401 & 2 & 2 & Met \\
\hline Preconditioning & Elongation factor- $1 \alpha$ & 6856354 & 4 & 2 & TT \\
\hline Preconditioning & Fascin homolog 1 & 6679745 & 3 & 3 & SCM \\
\hline Preconditioning & HSP-70 (heat shock 70 kDa protein 5) & 25742763 & 2 & 2 & ISR \\
\hline Preconditioning & HSP-60 (60 kDa heat shock protein) & 51702230 & 4 & 3 & ISR \\
\hline Preconditioning & Inosine monophosphatase & 40018566 & 4 & 2 & Met \\
\hline Preconditioning & MAP 1B (microtubule-associated protein 1B) & 1083716 & 3 & 3 & $\mathrm{SCM}$ \\
\hline Preconditioning & MARCKS (myristoylated alanine-rich C-kinase substrate) & 27705710 & 2 & 2 & ST \\
\hline Preconditioning & $\mathrm{Na}^{+} / \mathrm{K}^{+}$ATPase $\beta 1$ subunit & 6978549 & 2 & 2 & Met \\
\hline Preconditioning & NCAM-1 (neural cell adhesion molecule 1) & 13928706 & 3 & 2 & $\operatorname{Rec}$ \\
\hline Preconditioning & Phosphopyruvate hydratase & 109215 & 3 & 2 & Met \\
\hline Preconditioning & Pigpen (rat homolog) & 34859348 & 2 & 2 & TT \\
\hline Preconditioning & Plasma membrane calcium-transporting ATPase 1 & 14286099 & 5 & 3 & Met \\
\hline Preconditioning & Protein disulfide-isomerase A6 precursor & 2501206 & 3 & 3 & Met \\
\hline Preconditioning & Tubulin b5 protein & 38014544 & 5 & 3 & $\mathrm{SCM}$ \\
\hline Preconditioning & Vimentin & 14389299 & 7 & 7 & $\mathrm{SCM}$ \\
\hline
\end{tabular}

Proteins identified in P62 pull-down followed by mass spectrometry. Criteria for inclusion are listed in the Materials and Methods section, but include at least two unique peptide sequences for an identified protein. Proteins identified in both control and $\mathrm{OGD}$ are listed in the supplemental data (available at www.jneurosci.org as supplemental material). GI number, GenBank identification number; Met, metabolism; ISR, inflammatory stress response/defense proteins; ST, signal transduction/second messenger; SCM, sub-cell matrix and structural proteins; Rec, receptor; TT, transcription/translation.

supplemental material) and by mass spectrometry (supplemental Fig. $1 B$, available at www.jneurosci.org as supplemental material). After pull-down of proteins from control or preconditioned tissue, we performed one-dimensional gel electrophoresis and subjected gel sections to mass spectrometric analysis. Candidate proteins were considered for further analysis if the identifying peptides met the mass spectrometry criteria for high confidence (see Materials and Methods). Analysis of proteins identified by mass spectrometry yielded a list of seven proteins exclusive to control samples and 17 proteins in OGD-treated (preconditioned) samples (Table 1). In addition, 34 proteins were identified as being present in both samples; these were excluded from further analysis (supplemental Table 1, available at www. jneurosci.org as supplemental material). When we subdivided the candidate proteins by potential function, we found that 16 of the 24 proteins exclusive to control or preconditioned tissue resided in the postsynaptic density or interacted with proteins and signaling pathways in the postsynaptic density (see Table 1) (Husi et al., 2000; Husi, 2004).

The postsynaptic density is regulated by the ubiquitin-proteasome system (Ehlers, 2003). Actin is the major cytoskeletal protein regulating the highly dynamic structure of postsynaptic sites, especially dendritic spines. Accordingly, we focused our studies on two candidate proteins among those associated with the PSD that have actin-binding functions, fascin and MARCKS. Fascin, a $55 \mathrm{kDa}$ protein, contains two actin-binding domains and crosslinks actin filaments. Fascin plays a role in development and polarity of filopodia (early neurites) as well as growth cones (Kureishy et al., 2002). MARCKS is a $30 \mathrm{kDa}$ protein (Wu et al., 1982) (but migrates at $80 \mathrm{kDa}$ on SDS-PAGE). MARCKS links and anchors the plasma membrane to the actin cytoskeleton (Hartwig et al., 1992). We further analyzed each of these proteins for PEST sequences [a predictor of proteolytic degradation (Rechsteiner and Rogers, 1996)] using the Pestfind algorithm (http://www.
at.embnet.org/embnet/tools/bio/PESTfind/). Both MARCKS and fascin contain PEST sequences (three and five PEST sites, respectively) and thus were subject to further investigation to identify their role in rapid ischemic tolerance.

Immunoblot analysis shows that levels of MARCKS and fascin are decreased $1 \mathrm{~h}$ after $30 \mathrm{~min}$ preconditioning ischemia $(\sim 77$ and $67 \%$ of control, respectively) (Fig. $2 A$, supplemental Fig. $3 A$, available at www.jneurosci.org as supplemental material). The degradation of both MARCKS and fascin was blocked by the proteasome inhibitor MG132 (Fig. 2A, supplemental Fig. 3A, available at www.jneurosci.org as supplemental material), which also blocks rapid ischemic tolerance (Fig. $1 B$ ) (Meller et al., 2006). In contrast, actin levels did not change after PC or treatment with MG132 (Fig. 2 A). After preconditioning ischemia, the binding of actin to both fascin and MARCKS was reduced to $40 \%$ of control values (Fig. $2 B$, quantified in supplemental Fig. $3 B$, available at www.jneurosci.org as supplemental material). The immunoprecipitation of MARCKS and fascin with actin was 93 and $62 \%$ of control values, when cells were preconditioned and then treated with the proteasome inhibitor MG132 (Fig. 2 B, supplemental Fig. 3, available at www.jneurosci.org as supplemental material). We did note that the immunoprecipitation of both MARCKS and fascin with actin was also reduced in cells treated with MG132 for $1 \mathrm{~h}$. However, MG132 did not affect basal MARCKS or fascin protein levels (Fig. 2A), and immunocytochemical staining patterns for MARCKS were similar between control and MG132 treated cells (data not shown): the significance of this observation is not clear, but is under further investigation. Together, these data suggest that MARCKS and fascin are degraded by the ubiquitin-proteasome system after preconditioning ischemia, and this accounts for their reduced binding to actin.

We further investigated the localization of fascin and MARCKS after preconditioning using immunocytochemistry. 
A
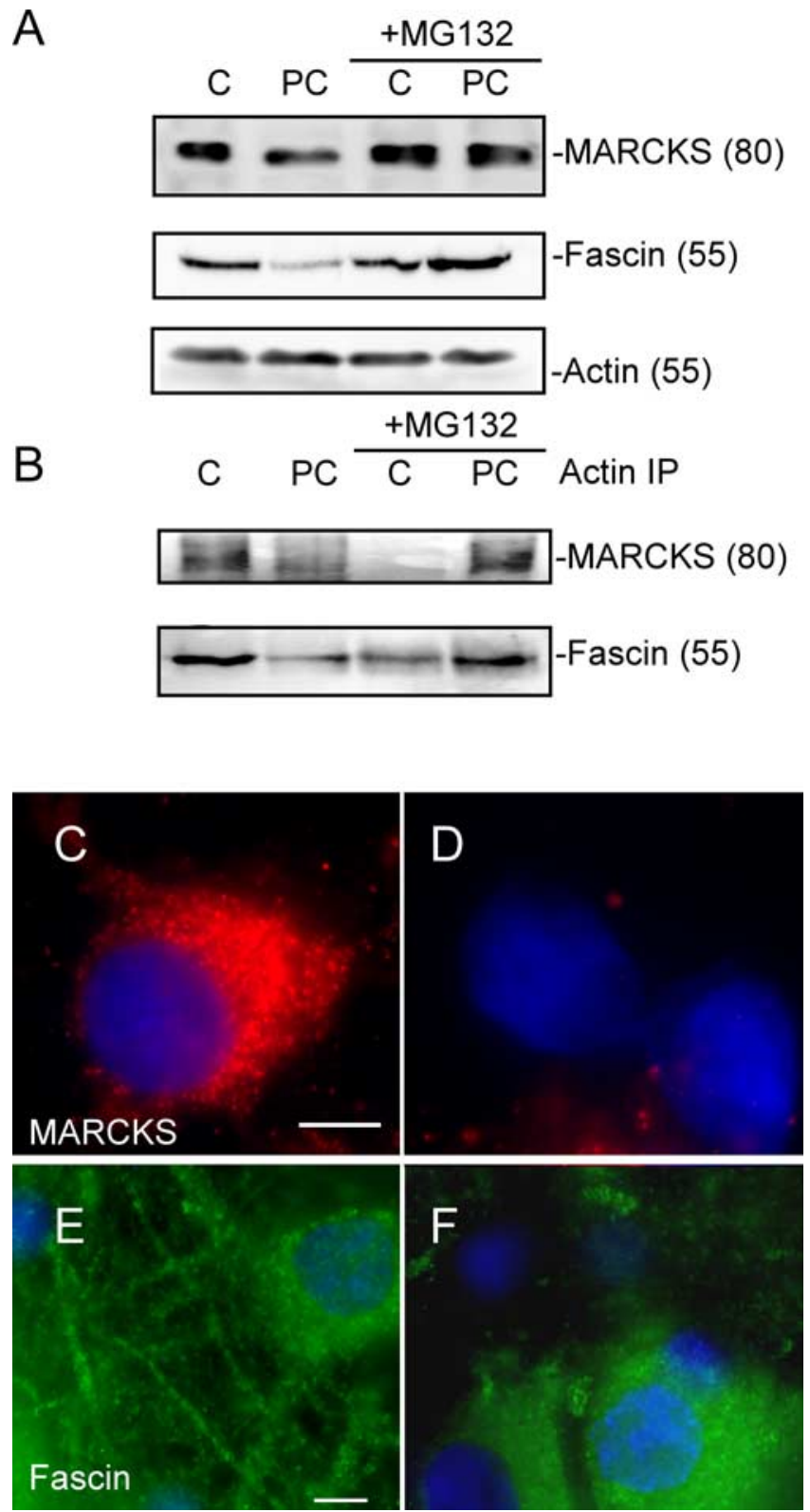

Figure 2. Degradation of MARCKS and fascin after preconditioning ischemia. $\boldsymbol{A}$, Immunoblot images of MARCKS, fascin, and actin protein levels in control (C) and $1 \mathrm{~h}$ after $\mathrm{PC}(30 \mathrm{~min}$ OGD) showing a reduction in fascin and MARCKS, but not actin protein levels after $P C$ that is reversed by MG132 $(0.1$ $\mu \mathrm{m})$. Blots are representative images of four and six independent experiments, respectively. Data are quantified in supplemental Figure $3 A$ (available at www.jneurosci.org as supplemental material). $\boldsymbol{B}$, Immunoblot of MARCKS and fascin after immunoprecipitation of actin in cells subject to preconditioning, showing reduced interaction of actin with MARCKS and fascin after PC that is reversed by MG132. Blots are representative images of three and four independent experiments, respectively. Data are quantified in supplemental Figure $3 B$ (available at www.jneurosci.org as supplemental material). $C$, $D$, MARCKS immunostaining in control neuronal cultures $(\boldsymbol{C})$ and $1 \mathrm{~h}$ after preconditioning ischemia (D). MARCKS staining was reduced after preconditioning ischemia. MARCKS (red) and DAPI (blue) staining were visualized using a $100 \times$ oil-immersion objective. Scale bar, $20 \mu \mathrm{m}$. E, F, Fascin immunostaining in neuronal cultures. $\boldsymbol{E}$, Note process-like staining pattern in control untreated cells. $\boldsymbol{F}$, Fascin staining after preconditioning ischemia and $1 \mathrm{~h}$ recovery. Note translocation of fascin to cell soma. Fascin staining (green) was visualized using a $40 \times$ objective. Scale bar, $20 \mu \mathrm{m}$. Images shown are representative images of at least two experiments. All experiments were performed on cortical neurons in culture at $10-14$ DIV.

Immunocytochemical studies of MARCKS (Fig. 2C,D) confirm our immunoblot data; fewer cells show MARCKS protein staining after ischemia ( $40 \%$ vs $20 \%$ of DAPI-positive cells). In control cells, fascin staining appears localized with neuronal pro- cesses, with only modest amounts present in the soma (Fig. 2E). After preconditioning ischemia, the fascin staining in the dendritic processes appear reduced, but was more pronounced in the cell soma (Fig. $2 F$ ).

Cytoskeleton reorganization after preconditioning ischemia To determine the effect of preconditioning ischemia-induced MARCKS and fascin degradation on the actin cytoskeleton, we used phalloidin to stain for filamentous actin. In control cells, actin staining revealed a punctate pattern along dendritic processes (Fig. $3 A, C$ ). The punctate staining of phalloidin was reduced to $68 \%$ of control levels $1 \mathrm{~h}$ after preconditioning ischemia (Fig. 3E). Furthermore, $1 \mathrm{~h}$ after preconditioning ischemia we observed a more filamentous staining pattern in the dendritic shaft of the cell and in the cell soma (Fig. $3 B, D$ ). The phalloidinstaining pattern returned to normal at $4 \mathrm{~h}$ after preconditioning ischemia (data not shown).

To support the phalloidin data showing changes in actin localization, cell lysates were prepared and centrifuged to separate globular actin (G-actin) remaining in the supernatant from filamentous actin (F-actin) in the pellet. The ratio of G-actin to F-actin after preconditioning ischemia was measured (Fig. $3 F, G)$. Immediately after preconditioning ischemia, the ratio of $\mathrm{G}$-actin/F-actin did not change compared with control $0 \mathrm{~h}$ (Fig. $3 F)$. Rather, the solubilization of F-actin occurred 0.5 and $1.0 \mathrm{~h}$ after preconditioning ischemia (Fig. $3 F$ ).

The functional significance of actin reorganization in rapid ischemic tolerance was demonstrated in cells incubated with the actin stabilizer jasplakinolide (Halpain et al., 1998). Jasplakinolide blocked 30 min OGD-induced rapid ischemic tolerance, but had no significant harmful effect on basal or 120 min OGDinduced cell death (data not shown) (Fig. $3 H$ ). The concentration of jasplakinolide used in this study stabilized F-actin content of the cells of the cells after ischemia (data not shown). Together these data show that preconditioning ischemia induces a reorganization of actin and that increased stabilization of filamentous actin using jasplakinolide prevents preconditioning-induced rapid ischemic tolerance.

\section{Changes to postsynaptic morphology after preconditioning ischemia}

To establish the morphological consequence of preconditioning ischemia-induced actin reorganization, we used the lipophilic membrane dye DiO to stain and assess dendritic spines in neurons. In control neurons, spines were visible on dendrites at a density of $4.3 \pm 0.3$ spines per $10 \mu \mathrm{m}$ length (mean \pm SEM, $n=$ 8) (Fig. $4 A, B$ ). The density of dendritic spines on our cultured neurons was similar to other studies using DiO- and GFPtransfected neurons (4.5 spine/10 $\mu \mathrm{m}$ length) (Hasbani et al., 2001a,b; Kirov et al., 2004; Zha et al., 2006). The density of spines was not significantly different across primary (abutting the cell soma), secondary (abutting primary dendrites), or tertiary (abutting secondary processes) processes $(4.3 \pm 0.22,4.3 \pm 0.3$, and $4.4 \pm 0.3$ spines per $10 \mu \mathrm{m}$ dendrite length, respectively). In cells preconditioned with $30 \mathrm{~min}$ OGD (PC) subject to $1 \mathrm{~h}$ recovery, dendritic spine density was reduced to $0.90 \pm 0.3$ spines per 10 $\mu \mathrm{m}$ length (Fig. $4 C, D$ ) uniformly over primary, secondary, and tertiary dendrites $(1.02 \pm 0.3,0.91 \pm 0.3$, and $0.77 \pm 0.3$ spines per $10 \mu \mathrm{m}$ dendrite length, respectively) (Fig. $4 F$ ). The number of dendritic spines was not significantly different from control levels $4 \mathrm{~h}$ after preconditioning ischemia (Fig. $4 E$ ), the time point when neuroprotection is lost (Meller et al., 2006). The proteasome inhibitor MG132 and the actin stabilizer jasplakinolide 

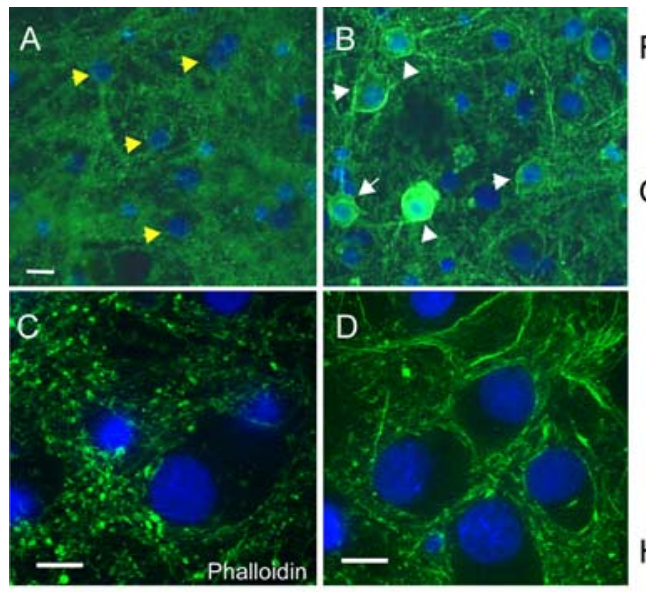

\section{F}
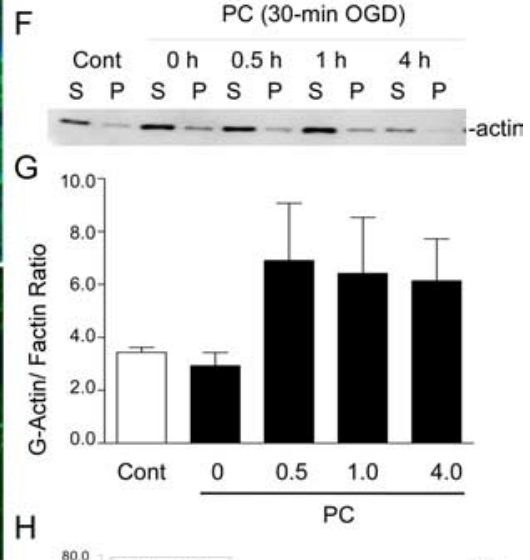

E
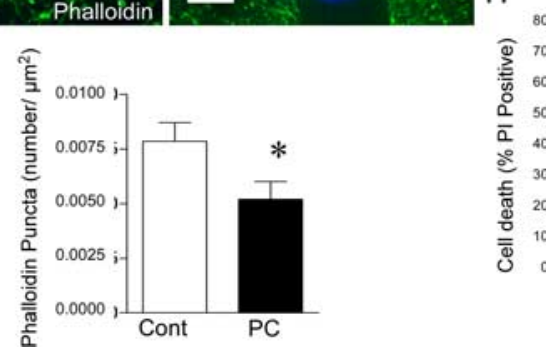

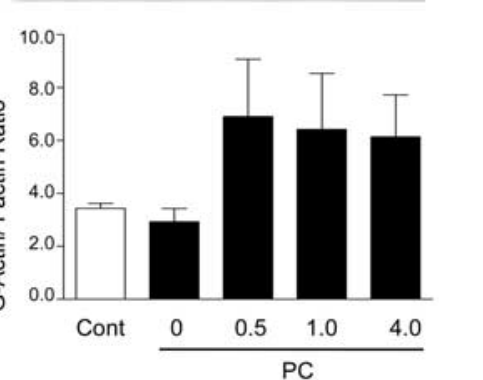

पuntreated

Jasplakinolide

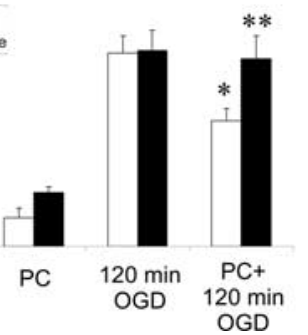

Figure 3. Reorganization of actin after preconditioning ischemia. $A$, Actin filaments are revealed by staining with phalloidin (conjugated with Oregon green 488). B, One hour after PC (30 min OGD), the staining pattern changes from punctate to filamentous, with staining also observed around the cell body. Phalloidin (green) and DAPI (blue) staining were visualized using a $40 \times$ objective. Scale bar, $20 \mu \mathrm{m}$. Arrows denote cells in control (yellow) and preconditioned cells (white). C, D, Highermagnification images $(100 \times)$ of phalloidin staining in control $(\boldsymbol{C})$ and preconditioned cells recovered for $1 \mathrm{~h}(\boldsymbol{D})$. Images were acquired using a Zeiss Apotome. Scale bar, $10 \mu \mathrm{m}$. E, Quantification of puncta in control and preconditioned cells. Data shown are mean \pm SEM $(n=6)$. $\boldsymbol{F}$, Solubilization of filamentous F-actin [in pellet (P)] into globular G-actin [in supernatant $(S)$ ] after preconditioning ischemia. After separation, actin was visualized by immunoblotting. Data shown are mean $\pm \operatorname{SEM}(n=3)$. The ratio of F-actin to G-actin was determined using a kit (Cytoskeleton, Denver, $(0)$. G, Quantitation of G-actin/F-actin ratios. Data shown are mean \pm SEM $(n=3)$. $\boldsymbol{H}$, Rapid ischemic tolerance is blocked by the actin-stabilizing compound jasplakinolide. Addition of jasplakinolide $(1.0 \mu \mathrm{m})$ to cells after PC blocks the preconditioning-induced neuroprotection. Data shown are mean \pm SEM $(n=5)$. ${ }^{*} p<0.05$ versus 120 min $0 G D ;{ }^{* *} p<0.05$ versus $P C+120$ min $0 G D$. All experiments were performed on cortical neurons in culture at 10-14 DIV.

block preconditioning-induced neuroprotection (Figs. $1 \mathrm{~B}, 3 \mathrm{H}$ ). Both the actin stabilizer jasplakinolide and MG132 significantly blocked the loss of dendritic spines on all processes after preconditioning ischemia (Fig. $4 G$, supplemental Fig. $2 A$, available at www.jneurosci.org as supplemental material). However, neither jasplakinolide nor MG132 alone had a significant effect on spine density in non-ischemia-treated cells (Fig. 4G, supplemental Fig. $2 \mathrm{~A}$, available at www.jneurosci.org as supplemental material).

After preconditioning ischemia, the dendrites also exhibit swelling and the appearance of varicosities (Fig. 4C,D). The varicosity formations were reduced $4 \mathrm{~h}$ after exposure to preconditioning ischemia (Fig. 5A). Unlike the effect of ischemia on spine loss, more varicosities were formed on tertiary dendrites than on primary dendrites abutting the cell soma (Fig. $5 B$ ). We also visualized dendrite varicosity formation using microtubuleassociated protein 2 (MAP2) immunocytochemistry. MAP2 was uniformly distributed in the dendrites of control cells (Fig. 5C), but after preconditioning ischemia the MAP2 staining appeared beaded on dendrites (Fig. 5D). MG132 and jasplakinolide reduced the formation of varicosities after preconditioning ischemia (Fig. 5E). When analyzed separately, jasplakinolide was less effective at reducing primary and secondary dendrite varicosity formation (supplemental Fig. $2 B$, available at www.jneurosci.org as supplemental material). These data suggest that after preconditioning ischemia the ubiquitin-proteasome system mediates

dendritic spine loss and varicosity formation that results in changes in neuronal morphology, which may serve as a protective phenotype.

\section{Reduced NMDA receptor-mediated function and toxicity after preconditioning ischemia}

Dendritic spines constitute the predominant site of synaptic input into neurons. To determine whether there was a functional correlate of dendritic spine changes, we investigated NMDA receptor-mediated responses in neurons after preconditioning ischemia. No change in NMDA receptor subunit expression was observed after preconditioning ischemia (Fig. 6A, quantified in supplemental Fig. $3 C$, available at www. jneurosci.org as supplemental material). However, the precipitation of both the NMDA $2 \mathrm{~B}$ receptor subunit and the postsynaptic density-associated structural protein PSD-95 with actin was decreased by $40 \%$, in cells after preconditioning, an effect partially reversed by the proteasome inhibitor MG132 (Fig. 6B, supplemental Fig. $3 D$, available at www.jneurosci.org as supplemental material). These findings suggest that preconditioning ischemia results in the reconfiguration of postsynaptic receptors and associated signaling scaffolds with the actin cytoskeleton, both of which would impact postsynaptic signaling.

Prolonged NMDA receptor activation is toxic to neurons (Choi et al., 1988). To test whether postsynaptic responses to NMDA were changed after preconditioning ischemia, we measured NMDA-stimulated electrophysiological responses using whole-cell patch configuration. Peak currents elicited by NMDA application (100 $\mu \mathrm{M}: 2 \mathrm{~s})$ were reduced by $30 \%$ in cells after preconditioning when compared with control (Fig. 6C,D). We also examined NMDAmediated cell death in cortical neurons after preconditioning. NMDA (200 $\mu \mathrm{M}: 60 \mathrm{~min})$ resulted in $44 \%$ cell death in cortical cultures (Fig. 6E). NMDA-induced cell death was reduced by $50 \%$ in cells after preconditioning ischemia $1 \mathrm{~h}$ before application of NMDA (Fig. $6 E$ ). The rapid tolerance to NMDA was blocked by proteasome inhibition with MG132 and actin stabilization with jasplakinolide (Fig. 6E). Together, these data are compatible with the morphologic alterations associated with preconditioning changing the structural relationship of NMDA receptors to the postsynaptic density, resulting in an attenuation of excitotoxic signaling mechanisms.

\section{Discussion}

The mechanism by which the brain acquires rapid ischemic tolerance is unknown. Here we reveal a novel mechanism by which neurons become rapidly tolerant to ischemia in a protein synthesis-independent manner and describe the tolerant phenotype acquired by the cell after the preconditioning process. We show that the downregulation of actin-binding structural proteins, mediated by the ubiquitin-proteasome system, results in actin reorganization, the retraction of dendritic spines, and 


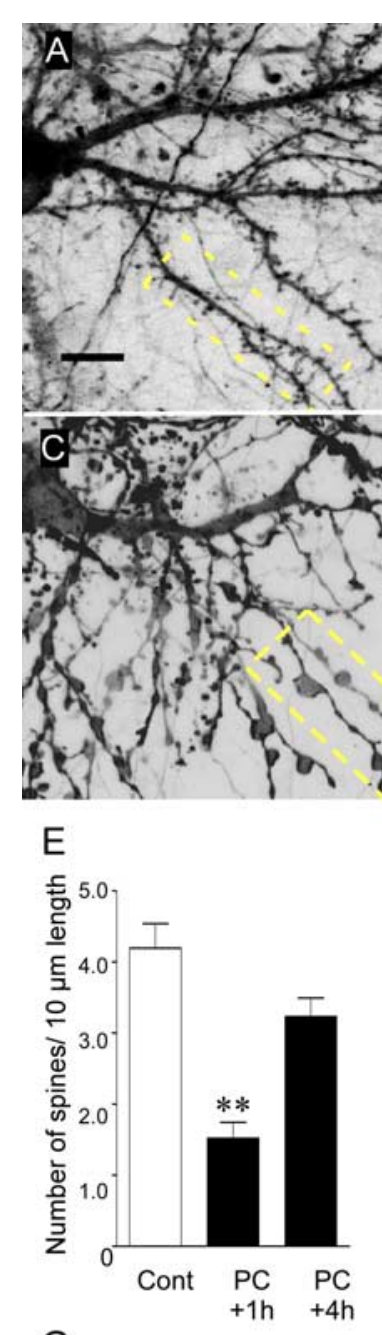

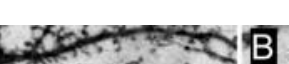

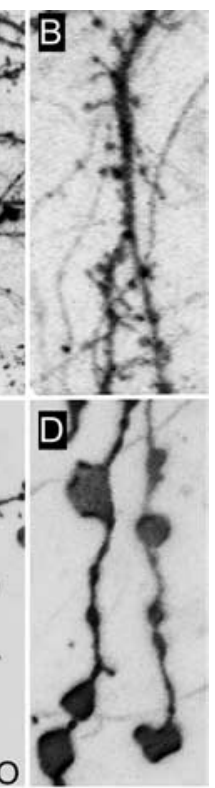

$\mathrm{F}$

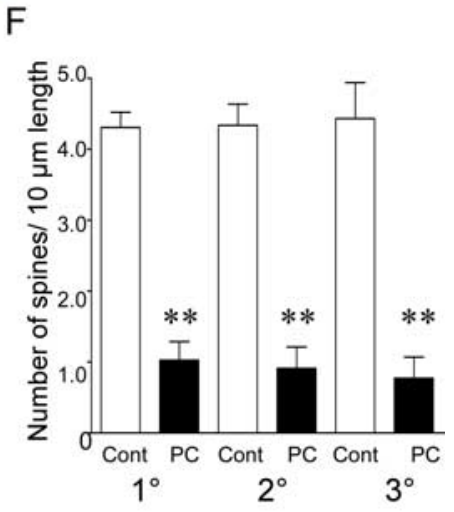

A
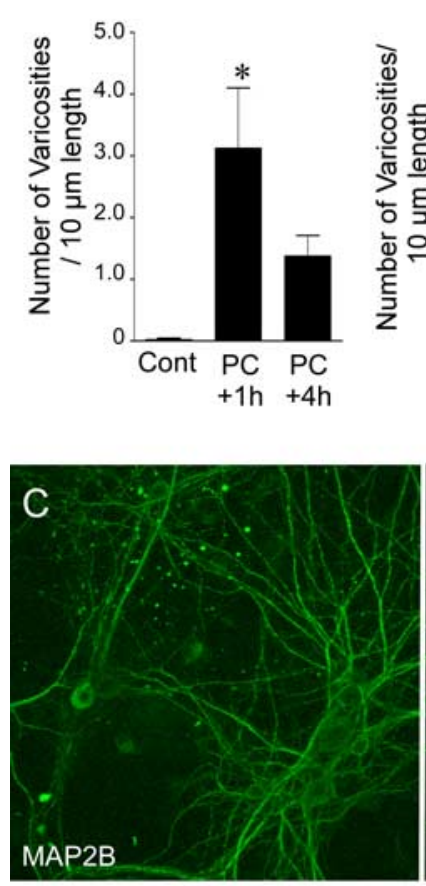

$E$

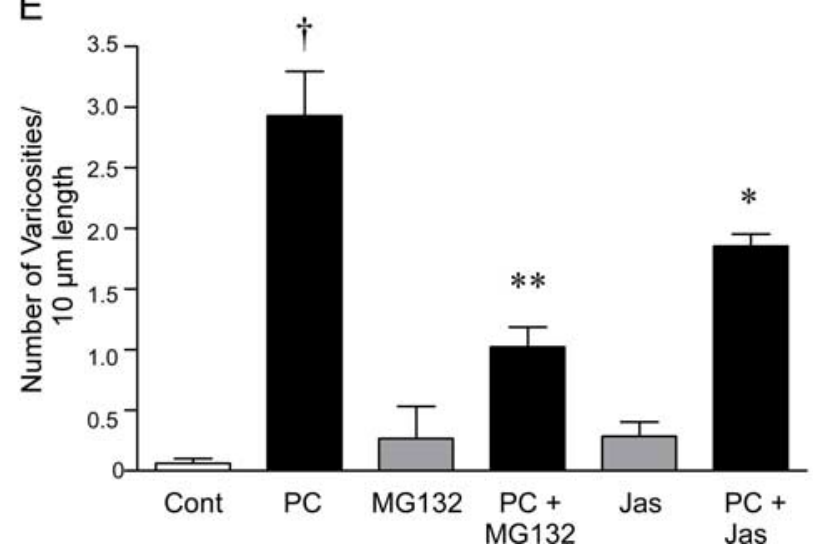

Figure 5. Preconditioning ischemia induces formation of varicosities on dendrites. $A$, Quantification of number of varicosities 1 and $4 \mathrm{~h}$ after $P C$ ( $30 \mathrm{~min}$ OGD). Data shown are mean \pm SEM $(n=4) .{ }^{*} p<0.05$ versus control. $\boldsymbol{B}$, Analysis of varicosity density by dendrite location. Dendrites were determined to be primary (touching the cell soma), secondary (contacting a primary), or tertiary (contacting a secondary). Data shown are mean $\pm \operatorname{SEM}(n=4) .{ }^{* *} p<$ 0.01 versus control. C, D, MAP 2 immunocytochemistry (green) in control $(\boldsymbol{C})$ and preconditioned cells $(\boldsymbol{D})$. Scale bar, $20 \mu \mathrm{m}$. $\boldsymbol{E}$, Some cultures received the proteasome inhibitor MG132 $(0.1 \mu \mathrm{M})$ or the actin stabilizer jasplakinolide $(1.0 \mu \mathrm{M})$ (Jas) after the PC. Varicosity density was determined $1 \mathrm{~h}$ after preconditioning ischemia, as above using Di0 staining. A further breakdown of the compound effects on varicosities by region is in supplemental Figure $2 B$ (available at www.jneurosci.org as supplemental material). Data shown are mean $\pm \operatorname{SEM}(n=4) .{ }^{\dagger} p<$ 0.001 versus control; ${ }^{*} p<0.05,{ }^{* *} p<0.01$ versus PC. All experiments were performed on cortical neurons in culture at $10-14$ DIV.

changes in postsynaptic NMDA receptor-mediated signaling. These transient structural changes result in neuroprotection to ischemia and represent a novel approach to regulate cell death after harmful ischemia.

Protein modification by ubiquitination is a central feature of brain ischemia. Protein ubiquitination increases after harmful levels of ischemia, which may result in accumulation of protein aggregates and contribute to cell stress (Hu et al., 2000). Hypo- 
A

A

C PC C PC

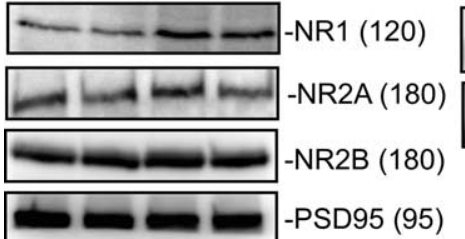

C
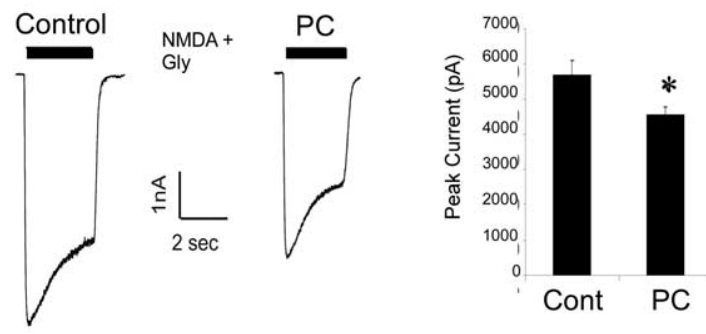

$\mathrm{E}$

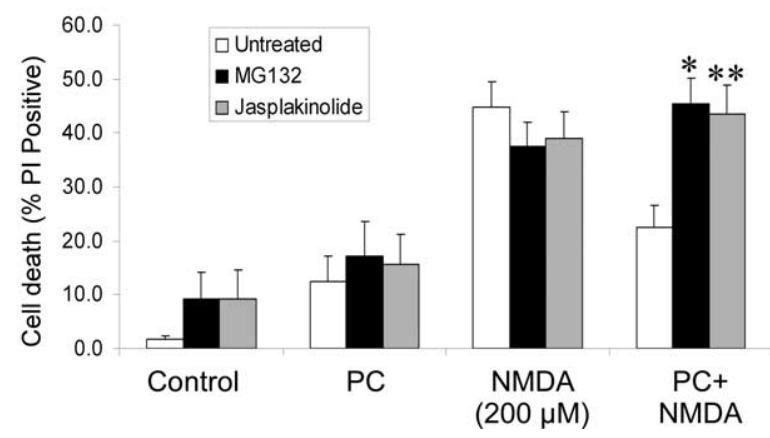

Figure 6. Uncoupling of NMDA receptors from the actin cytoskeleton and reduced excitotoxicity in rapid ischemic tolerance. $\boldsymbol{A}$, Immunoblot images showing the expression of NR1, NR2A, NR2B, and PSD-95 protein expression in controls (C) and $1 \mathrm{~h}$ after PC ( 30 min 0GD). Data shown are representative images of three independent experiments, respectively. Data are quantified in supplemental Figure 3C (available at www.jneurosci.org as supplemental material). $\boldsymbol{B}$, Immunoblot images showing expression of NR2B and PSD-95 after actin immunoprecipitation. Note the loss of NR2B and PSD-95 association with actin after preconditioning ischemia. Data shown are representative images of four experiments. Data are quantified in supplemental Figure 3D (available at www.jneurosci.org as supplemental material). C, Wholecell patch-clamp recording show a smaller peak current in response to NMDA in cells preconditioned with $30 \mathrm{~min} O G D(P C)$. Currents are recorded by voltage clamp and exposing the cells to $200 \mu \mathrm{m} \mathrm{NMDA}$ and $5 \mu \mathrm{m}$ glycine $1 \mathrm{~h}$ after the preconditioning stimulus. D, Quantification of electrophysiological recordings. Data shown are mean \pm SEM $(n=18$ and 17$)$. ${ }^{*} p<0.05$ versus control cells. $E$, Preconditioning induces tolerance to NMDA excitotoxicity. After PC (30 min 0GD) and $1 \mathrm{~h}$ recovery, cells were incubated with $200 \mu \mathrm{m}$ NMDA for $1 \mathrm{~h}$, and then cell death was assessed $24 \mathrm{~h}$ later. Preconditioning the cells reduced the toxic effects of NMDA. The protection against NMDA was reduced in cells incubated with either MG132 $(0.1 \mu \mathrm{M})$ or jasplakinolide $(1.0 \mu \mathrm{m})$ for $1 \mathrm{~h}$ after the preconditioning ischemia. Data shown are mean $\pm \mathrm{SEM}(n=7)$. ${ }^{\dagger} p<0.05$ versus NMDA; ${ }^{*} p<0.05$ versus $\mathrm{PC}+\mathrm{NMDA}^{* *} p<0.01$ vs $\mathrm{PC}+\mathrm{NMDA}$. All experiments were performed on cortical neurons in culture at 10-14 DIV.

thermia or ischemic preconditioning prevent protein ubiquitination after harmful levels of ischemia (Liu et al., 2005, 2006). In addition, proteasome inhibitors have been shown to block the activation of the transcription factor NF- $\kappa \mathrm{B}$ after harmful ischemia (Williams et al., 2004), resulting in protection. However, protein ubiquitination can also result in the selective and rapid downregulation of cell death-associated proteins, such as Bim, to induce the neuroprotective state of rapid ischemic tolerance (Meller et al., 2006). In this current study, we show that multiple inhibitors of the proteasome (MG132, MG115, and clasto- lactacystin- $\beta$-lactone) block rapid ischemic tolerance-induced neuroprotection (Fig. $1 \mathrm{~B}$ ); hence, we investigated the global ubiquitination of proteins after preconditioning using a proteomics approach to identify mechanisms that may be relevant for the generation of a protective phenotype.

We began with a targeted proteomic analysis of ubiquitinated proteins in neuronal tissue after the induction of rapid ischemic tolerance modeled in vitro using an ubiquitin-binding pull-down assay (Fig. 1 A) (Meller et al., 2006). Among the 24 proteins identified by mass spectrometry (Table 1), 16 were associated with the postsynaptic density (Husi et al., 2000; Collins et al., 2004; Husi, 2004). It has previously been shown that proteins in the postsynaptic density are regulated by the ubiquitin-proteasome system and that these changes are activity related and reversible (Colledge et al., 2003; Ehlers, 2003; Bingol and Schuman, 2004; Joch et al., 2007). We show a structural component, evident during rapid tolerance, dendritic spine loss, which has been reported previously with sublethal doses of ischemia (Park et al., 1996; Hasbani et al., 2001a). The cytoskeleton protein actin regulates the structure and morphology of postsynaptic sites (dendritic spines) (Wu et al., 1982; Hartwig et al., 1992; Kureishy et al., 2002). Therefore we focused our investigation on two of our candidate proteins associated with the postsynaptic density that could affect both synaptic structure and function: the actinbinding proteins MARCKS and fascin.

Our data suggest that the degradation of MARCKS and fascin result in their reduced interaction with the actin cytoskeleton and relocation in the cell (Fig. 2A,B). Translocation of MARCKS from membrane to cytosol in muscle cells is mediated by protein kinase C (Disatnik et al., 2004). Interestingly, in our model we observe a blockade of rapid ischemic tolerance with the protein kinase C inhibitor calphostin C (R. Meller, unpublished observation). In a previous study using nontoxic doses of NMDA, Graber et al. (2004) reported that cathepsin B-mediated proteolysis of MARCKS results in dendritic spine collapse, but that the decrease in MARCKS was not blocked by the proteasome inhibitor MG132. Hence two preconditioning stimuli (NMDA and ischemia) may induce the same net result in the neuron to induce a tolerant phenotype (loss of MARCKS and dendritic spine collapse), but via different biochemical mechanisms.

Our data strongly support the view that actin reorganization is involved in the generation of the protective phenotype after preconditioning ischemia. Neurochemically, actin is found in two forms: G-actin (globular) polymerizes into F-actin (filamentous), which forms the cytoskeleton associated with the postsynaptic membrane (Zigmond, 2004). F-actin is involved in the cytoskeleton within dendritic spines, including those associated with glutamate clustering where the cytoskeleton may be in a dynamic state (Dai et al., 2000). Our data suggest that actin reorganization occurs after preconditioning ischemia, and blocking such reorganization (with jasplakinolide) blocks rapid ischemic tolerance (Fig. 3). The effect of preconditioning ischemia on actin has not been studied; however, some studies report that actin mRNA levels are constant after harmful ischemia, up to $7 \mathrm{~d}$ (Onodera et al., 1989; Minami et al., 1992), whereas other studies show increases in actin mRNA levels, which may be attributable to gliosis in these regions (Kondo et al., 1994). Recently it has been reported that after harmful ischemia, the actinregulating protein WAVE-1 forms a complex with Bcl-XL, sequestering the anti-apoptotic function of Bcl-XL (Cheng et al., 2007), although it is not clear whether this complex is formed or inhibited by preconditioning ischemia. Interestingly, we observed a decrease of WAVE-1 ubiquitination in our preconditioned cells (Table 1), and this is currently under further investigation.

Spine remodeling is thought to underlie synaptic plasticity as 
well as being a consequence of excitotoxicity. Our data show that dendritic spines undergo transient retraction after preconditioning ischemia, coincident with actin remodeling (Fig. 4). Although an active role of actin in regulating spine morphology has previously been described (Matus, 2000; Rao and Craig, 2000), here we show a novel role of the ubiquitin-proteasome system in mediating morphological changes to the synapse, rather than at the molecular level (Colledge et al., 2003; Ehlers, 2003). Previous studies have suggested that harmful ischemia results in permanent spine retraction, suggesting that spine retraction may be a marker underlying excitotoxic damage to the cell (Park et al., 1996; Hasbani et al., 2001a,b). Our data are in agreement with other studies identifying spine retraction as a protective response of the cell to ischemia and excitotoxicity (Hasbani et al., 2001a,b). Our view of spine retraction as a neuroprotective phenotype is further supported by other studies: hibernating arctic ground squirrels and hamsters have reduced numbers of dendritic spines associated with the ischemia tolerant state of torpor (Popov and Bocharova, 1992; Magarinos et al., 2006; von der Ohe et al., 2006). Furthermore, a loss of dendritic spines has been reported in long-term depression (Zhou et al., 2004), which has many similar features to ischemic tolerance (brief stimulation resulting in a loss of response to a given stimuli). Hence dendritic remodeling may induce a protected phenotype to cells, rendering them refractory to excitotoxic signaling.

A second morphologic feature associated with the tolerant state was the formation of varicosities along the dendritic arbor (Fig. 5). Such varicosities were originally considered cell death indicators resulting from excitotoxicity (Olney, 1971). More recent data show that varicosity formation and excitotoxic cell death occur through independent mechanisms; death is $\mathrm{Ca}^{2+}$ mediated, whereas varicosities are mediated by $\mathrm{Na}^{2+}$ flux and AMPA internalization (Ikegaya et al., 2001). NMDA-induced varicosity formation was found to induce transient, reversible neuroprotection by attenuating excitatory neurotransmission (Ikegaya et al., 2001). Thus the varicosity formation as well as spine loss may play a combined role in the protective phenotype of rapid ischemic tolerance.

NMDA receptors are anchored to the actin cytoskeleton via a number of intermediate proteins (Husi et al., 2000). After tolerance induction, NMDA receptor anchoring to the cytoskeleton is reduced (Fig. $6 \mathrm{~B}$ ). The loss of NMDA receptor subunit interactions with the postsynaptic scaffold has been shown to block ischemia-induced toxicity (Aarts et al., 2002) but exerts no short term effect on basal synaptic transmission or long-term potentiation formation in hippocampal cultures (Lim et al., 2003). Previous studies have shown that actin depolymerization reduces NMDA channel activity (Rosenmund and Westbrook, 1993). In agreement with these, we observe a reduction in NMDAmediated currents and excitotoxicity after preconditioning (Fig. $6 C, E)$. Because tolerance to NMDA excitotoxicity was blocked by a proteasome inhibitor and an actin stabilizer (Fig. 6E), this suggests the mechanism that results in protection against harmful ischemia also blocks NMDA excitotoxicity.

Recent studies suggest that NMDA receptor-mediated signaling can be split into pathological and physiological mechanisms (Biegon et al., 2004). For example, Hardingham and colleagues reported that NR2B receptors in extrasynaptic locations mediate cell death via abrogated CREB signaling (Hardingham and Bading, 2002; Hardingham et al., 2002). In addition, Liu et al. (2007) reported that NR2B subunit-containing NMDA receptors, whether synaptic or extrasynaptic, mediate harmful cell signaling, whereas NR2A subunit-containing NMDA receptors appear protective. Our data and that of Sattler et al. (2000) suggest that toxic ischemia-induced NMDA signaling is inhibited after loss of dendritic spines; however, the effect of dendritic spine collapse on NMDA receptor function is not yet fully clear and requires further investigation. However, it has been demonstrated that some NMDA signaling may be protective (Hardingham and Bading, 2002; Hardingham et al., 2002; Biegon et al., 2004). To this end, we have observed that NMDA-induced CREB phosphorylation is maintained in rapid tolerance (data not shown). Therefore, at the time point when cells display refractory tolerance to toxic stimuli, selective loss of toxic NMDA receptor signaling occurs, which is associated with the disassociation of the postsynaptic intracellular receptor complex.

In summary, we have described the biology of rapid ischemic tolerance, which induces protein synthesis-independent protection within $1 \mathrm{~h}$ of the preconditioning stimuli. Furthermore we offer a mechanism for the protection, the proteasomal degradation of structural proteins after their ubiquitination that results in a morphological phenotype (dendritic spine loss), and a functional effect (reduced NMDA excitotoxicity). Hence our findings of an endogenous pathway that selectively reduces excitotoxic mechanisms of cell death may have potential for devising rapid-acting strategies to protect against ischemia-induced brain injury.

\section{References}

Aarts M, Liu Y, Liu L, Besshoh S, Arundine M, Gurd JW, Wang YT, Salter MW, Tymianski M (2002) Treatment of ischemic brain damage by perturbing NMDA receptor-PSD-95 protein interactions. Science 298:846-850.

American Heart Association (2003) Heart disease and stroke statistics2003 update. Dallas, TX: American Heart Association.

Babu JR, Geetha T, Wooten MW (2005) Sequestosome 1/p62 shuttles polyubiquitinated tau for proteasomal degradation. J Neurochem 94:192-203.

Barone FC, White RF, Spera PA, Ellison J, Currie RW, Wang X, Feuerstein GZ (1998) Ischemic preconditioning and brain tolerance: temporal histological and functional outcomes, protein synthesis requirement, and interleukin-1 receptor antagonist and early gene expression. Stroke 29: 1937-1950; discussion 1950-1951.

Biegon A, Fry PA, Paden CM, Alexandrovich A, Tsenter J, Shohami E (2004) Dynamic changes in N-methyl-D-aspartate receptors after closed head injury in mice: implications for treatment of neurological and cognitive deficits. Proc Natl Acad Sci USA 101:5117-5122.

Bingol B, Schuman EM (2004) A proteasome-sensitive connection between PSD-95 and GluR1 endocytosis. Neuropharmacology 47:755-763.

Cheng A, Arumugam TV, Liu D, Khatri RG, Mustafa K, Kwak S, Ling HP, Gonzales C, Xin O, Jo DG, Guo Z, Mark RJ, Mattson MP (2007) Pancortin-2 interacts with WAVE1 and $\mathrm{Bcl}-\mathrm{xL}$ in a mitochondriaassociated protein complex that mediates ischemic neuronal death. J Neurosci 27:1519-1528.

Choi DW (1992) Excitotoxic cell death. J Neurobiol 23:1261-1276.

Choi DW, Koh JY, Peters S (1988) Pharmacology of glutamate neurotoxicity in cortical cell culture: attenuation by NMDA antagonists. J Neurosci 8:185-196.

Colledge M, Snyder EM, Crozier RA, Soderling JA, Jin Y, Langeberg LK, Lu H, Bear MF, Scott JD (2003) Ubiquitination regulates PSD-95 degradation and AMPA receptor surface expression. Neuron 40:595-607.

Collins MO, Yu L, Coba MP, Husi H, Campuzano I, Blackstock WP, Choudhary JS, Grant SG (2004) Proteomic analysis of in vivo phosphorylated synaptic proteins. J Biol Chem 280:5972-5982.

Dai Z, Luo X, Xie H, Peng HB (2000) The actin-driven movement and formation of acetylcholine receptor clusters. J Cell Biol 150:1321-1334.

Dirnagl U, Simon RP, Hallenbeck JM (2003) Ischemic tolerance and endogenous neuroprotection. Trends Neurosci 26:248-254.

Disatnik MH, Boutet SC, Pacio W, Chan AY, Ross LB, Lee CH, Rando TA (2004) The bi-directional translocation of MARCKS between membrane and cytosol regulates integrin-mediated muscle cell spreading. J Cell Sci 117:4469-4479.

Ehlers MD (2003) Activity level controls postsynaptic composition and signaling via the ubiquitin-proteasome system. Nat Neurosci 6:231-242. 
Gatlin CL, Kleemann GR, Hays LG, Link AJ, Yates III JR (1998) Protein identification at the low femtomole level from silver-stained gels using a new fritless electrospray interface for liquid chromatography-microspray and nanospray mass spectrometry. Anal Biochem 263:93-101.

Graber S, Maiti S, Halpain S (2004) Cathepsin B-like proteolysis and MARCKS degradation in sub-lethal NMDA-induced collapse of dendritic spines. Neuropharmacology 47:706-713.

Halpain S, Hipolito A, Saffer L (1998) Regulation of F-actin stability in dendritic spines by glutamate receptors and calcineurin. J Neurosci 18:9835-9844.

Hardingham GE, Bading H (2002) Coupling of extrasynaptic NMDA receptors to a CREB shut-off pathway is developmentally regulated. Biochim Biophys Acta 1600:148-153.

Hardingham GE, Fukunaga Y, Bading H (2002) Extrasynaptic NMDARs oppose synaptic NMDARs by triggering CREB shut-off and cell death pathways. Nat Neurosci 5:405-414.

Hartwig JH, Thelen M, Rosen A, Janmey PA, Nairn AC, Aderem A (1992) MARCKS is an actin filament crosslinking protein regulated by protein kinase $\mathrm{C}$ and calcium-calmodulin. Nature 356:618-622.

Hasbani MJ, Viquez NM, Goldberg MP (2001a) NMDA receptors mediate hypoxic spine loss in cultured neurons. NeuroReport 12:2731-2735.

Hasbani MJ, Schlief ML, Fisher DA, Goldberg MP (2001b) Dendritic spines lost during glutamate receptor activation reemerge at original sites of synaptic contact. J Neurosci 21:2393-2403.

Herrmann J, Lerman LO, Lerman A (2007) Ubiquitin and ubiquitin-like proteins in protein regulation. Circ Res 100:1276-1291.

Hu BR, Martone ME, Jones YZ, Liu CL (2000) Protein aggregation after transient cerebral ischemia. J Neurosci 20:3191-3199.

Husi H (2004) NMDA receptors, neural pathways, and protein interaction databases. Int Rev Neurobiol 61:49-77.

Husi H, Ward MA, Choudhary JS, Blackstock WP, Grant SG (2000) Proteomic analysis of NMDA receptor-adhesion protein signaling complexes. Nat Neurosci 3:661-669.

Ikegaya Y, Kim JA, Baba M, Iwatsubo T, Nishiyama N, Matsuki N (2001) Rapid and reversible changes in dendrite morphology and synaptic efficacy following NMDA receptor activation: implication for a cellular defense against excitotoxicity. J Cell Sci 114:4083-4093.

Joch M, Ase AR, Chen CX, Macdonald PA, Kontogiannea M, Corera AT, Brice A, Seguela P, Fon EA (2007) Parkin-mediated monoubiquitination of the PDZ protein PICK1 regulates the activity of acid-sensing ion channels. Mol Biol Cell 18:3105-3118.

Kirov SA, Goddard CA, Harris KM (2004) Age-dependence in the homeostatic upregulation of hippocampal dendritic spine number during blocked synaptic transmission. Neuropharmacology 47:640-648.

Kitagawa K, Matsumoto M, Tagaya M, Hata R, Ueda H, Niinobe M, Handa N, Fukunaga R, Kimura K, Mikoshiba K, et al (1990) "Ischemic tolerance" phenomenon found in the brain. Brain Res 528:21-24.

Kondo Y, Ogawa N, Asanuma M, Hirata H, Nishibayashi S, Mori A (1994) Regional changes in alpha-tubulin and beta-actin mRNA accumulations after transient ischemia in spontaneously hypertensive rat brains. Res Commun Mol Pathol Pharmacol 86:139-153.

Kureishy N, Sapountzi V, Prag S, Anilkumar N, Adams JC (2002) Fascins, and their roles in cell structure and function. BioEssays 24:350-361.

Lim IA, Merrill MA, Chen Y, Hell JW (2003) Disruption of the NMDA receptor-PSD-95 interaction in hippocampal neurons with no obvious physiological short-term effect. Neuropharmacology 45:738-754.

Liu C, Chen S, Kamme F, Hu BR (2005) Ischemic preconditioning prevents protein aggregation after transient cerebral ischemia. Neuroscience 134:69-80.

Liu JJ, Zhao H, Sung JH, Sun GH, Steinberg GK (2006) Hypothermia blocks ischemic changes in ubiquitin distribution and levels following stroke. NeuroReport 17:1691-1695.

Liu Y, Wong TP, Aarts M, Rooyakkers A, Liu L, Lai TW, Wu DC, Lu J, Tymianski M, Craig AM, Wang YT (2007) NMDA receptor subunits have differential roles in mediating excitotoxic neuronal death both in vitro and in vivo. J Neurosci 27:2846-2857.

Magarinos AM, McEwen BS, Saboureau M, Pevet P (2006) Rapid and reversible changes in intrahippocampal connectivity during the course of hibernation in Eur hamsters. Proc Natl Acad Sci USA 103:18775-18780.

Matus A (2000) Actin-based plasticity in dendritic spines. Science 290:754-758
Meller R, Skradski SL, Simon RP, Henshall DC (2002) Expression, proteolysis and activation of caspases 6 and 7 during rat C6 glioma cell apoptosis. Neurosci Lett 324:33-36.

Meller R, Minami M, Cameron JA, Impey S, Chen D, Lan JQ, Henshall DC Simon RP (2005) CREB-mediated Bcl-2 protein expression after ischemic preconditioning. J Cereb Blood Flow Metab 25:234-246.

Meller R, Cameron JA, Torrey DJ, Clayton CE, Ordonez AN, Henshall DC, Minami M, Schindler CK, Saugstad JA, Simon RP (2006) Rapid degradation of Bim by the ubiquitin-proteasome pathway mediates short-term ischemic tolerance in cultured neurons. J Biol Chem 281:7429-7436.

Minami M, Kuraishi Y, Yabuuchi K, Yamazaki A, Satoh M (1992) Induction of interleukin-1 beta mRNA in rat brain after transient forebrain ischemia. J Neurochem 58:390-392.

Olney JW (1971) Glutamate-induced neuronal necrosis in the infant mouse hypothalamus. An electron microscopic study. J Neuropathol Exp Neurol 30:75-90.

Onodera H, Kogure K, Ono Y, Igarashi K, Kiyota Y, Nagaoka A (1989) Proto-oncogene c-fos is transiently induced in the rat cerebral cortex after forebrain ischemia. Neurosci Lett 98:101-104.

Park JS, Bateman MC, Goldberg MP (1996) Rapid alterations in dendrite morphology during sublethal hypoxia or glutamate receptor activation. Neurobiol Dis 3:215-227.

Perez-Pinzon MA, Born JG (1999) Rapid preconditioning neuroprotection following anoxia in hippocampal slices: role of the K+ ATP channel and protein kinase C. Neuroscience 89:453-459.

Perez-Pinzon MA, Mumford PL, Rosenthal M, Sick TJ (1996) Anoxic preconditioning in hippocampal slices: role of adenosine. Neuroscience 75:687-694.

Popov VI, Bocharova LS (1992) Hibernation-induced structural changes in synaptic contacts between mossy fibres and hippocampal pyramidal neurons. Neuroscience 48:53-62.

Rao A, Craig AM (2000) Signaling between the actin cytoskeleton and the postsynaptic density of dendritic spines. Hippocampus 10:527-541.

Rechsteiner M, Rogers SW (1996) PEST sequences and regulation by proteolysis. Trends Biochem Sci 21:267-271.

Reshef A, Sperling O, Zoref-Shani E (1996) Preconditioning of primary rat neuronal cultures against ischemic injury: characterization of the "time window of protection." Brain Res 741:252-257.

Rosenmund C, Westbrook GL (1993) Calcium-induced actin depolymerization reduces NMDA channel activity. Neuron 10:805-814.

Sattler R, Xiong Z, Lu WY, MacDonald JF, Tymianski M (2000) Distinct roles of synaptic and extrasynaptic NMDA receptors in excitotoxicity. J Neurosci 20:22-33.

Shevchenko A, Wilm M, Vorm O, Mann M (1996) Mass spectrometric sequencing of proteins silver-stained polyacrylamide gels. Anal Chem 68:850-858.

Verma R, Deshaies RJ (2000) A proteasome howdunit: the case of the missing signal. Cell 101:341-344.

von der Ohe CG, Darian-Smith C, Garner CC, Heller HC (2006) Ubiquitous and temperature-dependent neural plasticity in hibernators. J Neurosci 26:10590-10598.

Williams AJ, Berti R, Dave JR, Elliot PJ, Adams J, Tortella FC (2004) Delayed treatment of ischemia/reperfusion brain injury: extended therapeutic window with the proteosome inhibitor MLN519. Stroke 35:1186-1191.

Wu WC, Walaas SI, Nairn AC, Greengard P (1982) Calcium/phospholipid regulates phosphorylation of a $\mathrm{Mr}$ " $87 \mathrm{k}$ " substrate protein in brain synaptosomes. Proc Natl Acad Sci USA 79:5249-5253.

Xiong ZG, Zhu XM, Chu XP, Minami M, Hey J, Wei WL, MacDonald JF, Wemmie JA, Price MP, Welsh MJ, Simon RP (2004) Neuroprotection in ischemia: blocking calcium-permeable acid-sensing ion channels. Cell 118:687-698.

Zigmond SH (2004) Beginning and ending an actin filament: control at the barbed end. Curr Top Dev Biol 63:145-188.

Zha XM, Wemmie JA, Green SH, Welsh MJ (2006) Acid-sensing ion channel $1 \mathrm{a}$ is a postsynaptic proton receptor that affects the density of dendritic spines. Proc Natl Acad Sci USA 103:16556-16561.

Zhou Q, Homma KJ, Poo MM (2004) Shrinkage of dendritic spines associated with long-term depression of hippocampal synapses. Neuron 44: $749-757$. 